\title{
TETRACYCLINE DEPOSITS IN CHILDREN'S TEETH IN RELATION TO ATMOSPHERIC POLLUTION
}

\author{
JOAN EGAN, F. C. TRING* AND R. E. S. PROUT \\ County Borough of Rotherham, and Department of Human Biology and Anatomy and Department of Biochemistry, \\ University of Sheffield
}

The tetracyclines have enjoyed astonishing popularity since their introduction in 1950. They appeared to have many advantages over other preparations then in vogue and soon became known as 'broad spectrum' antibiotics, a euphemism which probably encouraged their widespread use as prophylactic agents for upper respiratory tract disease occurring in children (Banks, 1968; Banks and Ritchie, 1969). However, as they became more extensively prescribed, a catalogue of side effects accumulated which prompted caution in their use (Mull, 1966).

One of the earliest hazards of tetracycline therapy to be suspected was discoloration of the teeth. This phenomenon was first observed in a highly selected series of child patients receiving prolonged courses of tetracycline (Shwachman and Schuster, 1956). Further reports quickly followed and amply confirmed the association between tooth discoloration and tetracycline therapy (Wallman and Hilton, 1962; Moynahan, 1962; Witkop and Wolf, 1963).

Tetracyclines fluoresce a golden yellow in ultraviolet light, a characteristic which enables their presence to be detected in mineralized tissues such as teeth and bone (Saltzman, 1950; Milch, Rall and Tobie, 1957). Once they have been incorporated into mineralizing tissues the tetracyclines remain for prolonged periods. Bone undergoes remodelling and eventually will lose any evidence of past tetracycline deposition, but teeth provide a permanent record of any tetracycline incorporated during their mineralization (Lancet, 1966).

The crowns of successional ('permanent') teeth become mineralized at various times which are more or less constant for a particular tooth form. The first ('permanent') molar tooth erupts into the mouth during the sixth year but its crown is formed and mineralized during the first four years after birth. Detection of tetracycline fluorescence in the crown of this tooth, therefore, indicates precisely definable areas of active mineralization incorporating

* Reprint requests to: F. C. Tring, Department of Human Biology and Anatomy, University of Sheffield, Sheffield S10 2TN. tetracycline at a specific age. This provides a means of monitoring the prevalence of tetracycline therapy administered at a particular age of a child (Baker and Storey, 1970; Grossman, Walchek, and Freedman, 1971).

The objects of the survey reported here are, first, to see whether the pattern of tetracycline administration has changed since the adverse effects of the drug became widely known and, secondly, to compare the levels of tetracycline deposits found in the teeth of children living in two towns with significant differences in their levels of atmospheric pollution.

\section{Materials and Methods}

Rotherham and Northallerton were selected for this study because they presented features which made them suitable towns for comparison. First, the drinking water supplied to each town showed insignificant differences in fluoride concentrations and therefore one group of school children was not protected (by systemic fluoride) from susceptibility to dental caries more than the other group. Secondly, the school children in each town attended central dental clinics which were not geographically selective in their catchment areas. Northallerton had a single central clinic and Rotherham had two. Thirdly, the two towns differed enormously in their levels of atmospheric pollution, Rotherham having a highly polluted atmosphere and Northallerton being almost pollution free.

From September 1970 to September 1971 first (permanent) molar teeth extracted from child patients aged 6 to 13 years were obtained from the Rotherham and Northallerton school dental clinics.

The first molar teeth used for this survey were required to fulfil two criteria:

(a) only one extracted molar tooth from a particular child was included in the survey; and

(b) at the time of extraction the tooth had had a vital pulp and a relatively intact crown.

To satisfy these requirements the teeth were obtained mainly from children undergoing therapeutic 
extractions to correct incipient malocclusion. Threehundred-and-eighty-three teeth were obtained from Rotherham and $\mathbf{2 8 9}$ from Northallerton and as only one tooth from one child was used the number of teeth examined represents the number of children included in the survey. Individual teeth were placed in separate containers, bearing details of age and identification, and were stored in darkness until required for preparation. Each tooth was then ground in a sagittal plane to a thickness of $200 \mu$, mounted in neutral glycerine, and examined under ultraviolet light. Fluorescent curvilinear bands occurring in the dentine of the tooth crowns were counted and tabulated.

\section{RESULTS}

Each fluorescent band observed indicated a separate course of tetracycline administration.

Examination of the crowns of the sectioned first molar teeth under ultraviolet light indicated that $80 \%$ of those teeth extracted from Rotherham school children and $64 \%$ of teeth from Northallerton school children showed tetracycline fluorescent curvilinear bands. As only one tooth per child was included in the survey these findings suggest that $80 \%$ of Rotherham school children and $64 \%$ of Northallerton school children included in these samples had received tetracycline at least once during their first four years of life (Table).

The percentage of children in different age groups who had received tetracycline showed differences between the two towns (Figure 1). Each locality showed a variation in the range of the number of tetracycline fluorescent bands (courses of treatment) (Figure 2) but the course frequency was higher for Rotherham.

TABLE

\begin{tabular}{|c|c|c|c|c|c|}
\hline \multirow{2}{*}{$\begin{array}{l}\text { Age of } \\
\text { Child }\end{array}$} & \multirow{2}{*}{$\begin{array}{l}\text { No. of } \\
\text { Teeth } \\
\text { Examined }\end{array}$} & \multirow{2}{*}{$\begin{array}{c}\% \\
\text { Showing } \\
\text { Fluorescence }\end{array}$} & \multirow{2}{*}{$\begin{array}{c}\text { Time of } \\
\text { Administration }\end{array}$} & \multirow{2}{*}{\multicolumn{2}{|c|}{$\begin{array}{c}\begin{array}{c}\text { Fluorescent } \\
\text { Crown Lines }\end{array} \\
\text { No. Mean }\end{array}$}} \\
\hline & & & & & \\
\hline $\begin{array}{c}\text { ROTHERH } \\
6-7 \\
8-9 \\
10-11 \\
12-13\end{array}$ & $\begin{array}{r}75 \\
98 \\
102 \\
108\end{array}$ & $\begin{array}{l}78 \\
75 \\
78 \\
88\end{array}$ & $\begin{array}{l}1965-70 \\
1963-68 \\
1961-66 \\
1959-64\end{array}$ & $\begin{array}{l}1-4 \\
1-6 \\
2-11 \\
4-11\end{array}$ & $\begin{array}{l}2 \cdot 3 \\
4 \cdot 2 \\
7 \cdot 2 \\
5 \cdot 9\end{array}$ \\
\hline TOTAL & 383 & 80 & & & \\
\hline $\begin{array}{c}\text { NORTHAL } \\
6-7 \\
8-9 \\
10-11 \\
12-13\end{array}$ & $\begin{array}{r}70 \\
68 \\
71 \\
80\end{array}$ & $\begin{array}{l}45 \\
75 \\
60 \\
77\end{array}$ & $\begin{array}{l}1965-70 \\
1963-68 \\
1961-66 \\
1959-64\end{array}$ & $\begin{array}{l}1-4 \\
1-4 \\
2-7 \\
2-9\end{array}$ & $\begin{array}{l}2 \cdot 8 \\
2 \cdot 8 \\
4 \cdot 1 \\
3 \cdot 6\end{array}$ \\
\hline TOTAL & 289 & 64 & & & \\
\hline
\end{tabular}

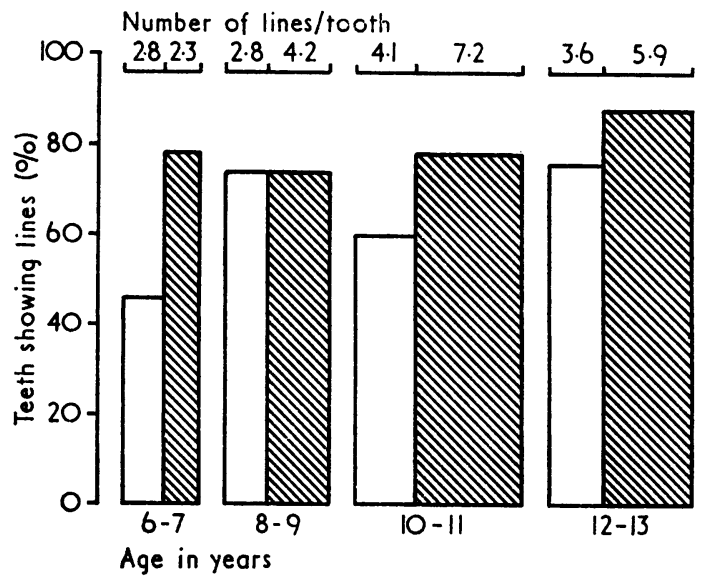

Fig. 1. Histogram of number of fluorescent crown lines per tooth (tetracycline courses) represented by width of columns, in different age groups as a percentage of teeth (number of children) showing tetracycline fluorescence. The open columns represent results from Northallerton; the hatched columns represent results from Rotherham.

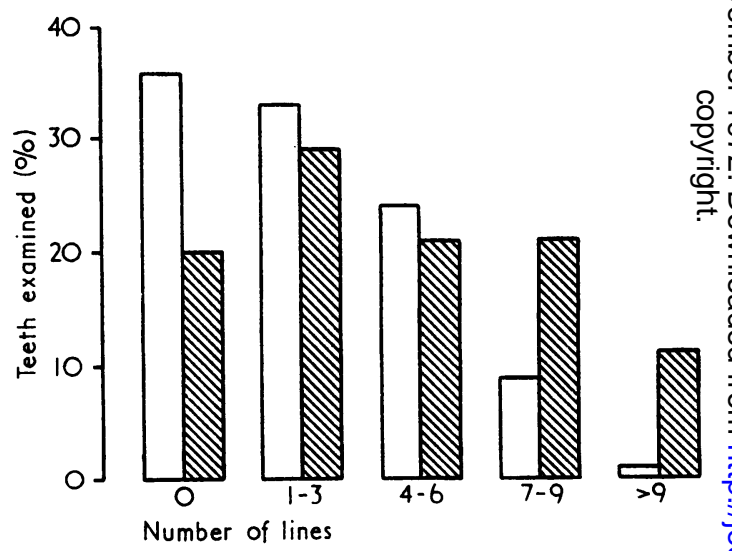

Fig. 2. Histogram of number of fluorescent crown lines (tetracycline courses per tooth per cent of teeth examined). The open columns represent the results from Northallerton, the hatched columns those from Rotherham.

When the fluorescent crown lines per 100 children for each age group are calculated there is an 은 indication that the frequency of tetracycline $D$ administration is tending to decline. There is an overall reduction of the number of fluorescent crown $N$ lines from the peak incidence occurring in 1961-1966 (Figure 3) in both Rotherham and Northallerton.

\section{Discussion}

Widespread publicity has been given to some of $\frac{0}{D}$ the undesirable side effects of tetracycline therapy $\stackrel{\mathcal{D}}{?}$ including tooth discoloration (Weyman, 1965). In 0 spite of the recognition of this hazard the prevalence . 


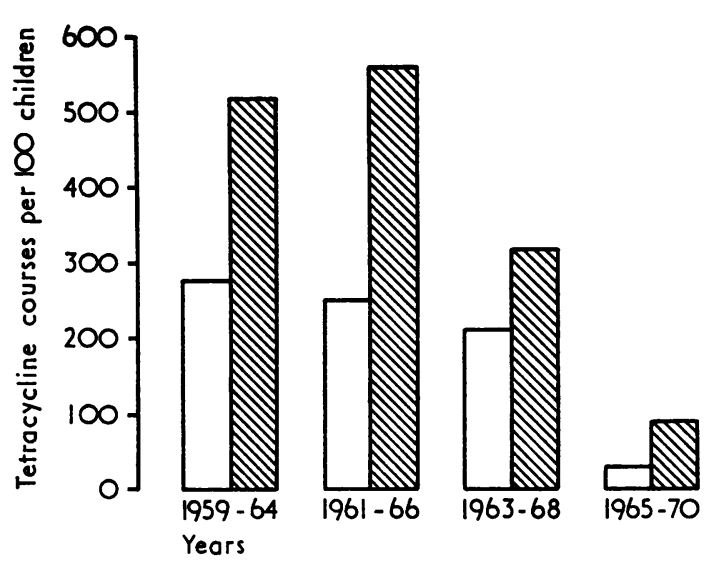

FIG. 3. Histogram of number of courses of tetracycline per 100 children, administered during period of calcification (age 0-4 years) of crowns of first molar (permanent) teeth. The dates of adminisof crowns of first molar (permanent) teeth. The dates of adminischildren, e.g., children aged between 12 and 13 years in 1970-71 were aged $0-4$ years in 1959-64. The open columns represent results from Northallerton and the hatched columns results from Rotherham.

of tetracycline deposits in children's teeth continues to be generally high (Stewart, 1968; Baker and Storey, 1970).

One reason for the high level of tetracycline in children's teeth is obviously related to the illnesses for which it is prescribed. The tetracyclines have been extensively used in minor respiratory tract infections occurring in children, their early use having been advocated within hours of the onset of symptoms and at least before the onset of evidence of secondarily infected nasal discharge (Banks and Ritchie, 1969). Apthorp (1969) pointed out that the clinical dilemma presented to general practitioners was whether or not to be early or late tetracycline prescribers.

Stewart (1968) pointed out that in a survey of this type a number of external factors could profoundly influence the results. These factors would include the population under review, the environment in which the population lived, and the individual preference of those prescribing the drug.

The major difference between the two groups of children we surveyed concerned their different environments. Rotherham had a very high level of atmospheric pollution measured by smoke and sulphur dioxide content. Although this level of pollution is slowly being reduced (MOH, Rotherham, 1970) it remains high and compares unfavourably with Northallerton where there is minimal atmospheric pollution. Atmospheric pollution has been shown to be a major contributory factor in the incidence of respiratory infection in children, such infection tending to decline as atmospheric pollution subsides (Lunn, Knowelden, and Roe, 1970). It appears likely, in view of the great differences in atmospheric pollution levels between Rotherham and Northallerton, that these would consequentially enhance differences in the incidence of respiratory tract infection and hence differences in requirement for tetracycline medication.

The prevalence of tetracycline deposits found in the teeth examined in this survey showed notable differences occurring between the two towns, Rotherham and Northallerton. The overall figure for Rotherham was $80 \%$, while the figure for Northallerton was significantly lower at $64 \%$. When teeth from children grouped according to age and showing tetracycline fluorescence in the crowns of teeth are compared, the results show a fall in incidence with decreasing age (Figure 3), indicating a trend that tetracycline is being administered less frequently. This figure, however, is higher for Rotherham than Northallerton, both in the number of children receiving tetracycline and in the dosage frequency (crown lines) (Figures 1 and 3).

The marked difference in the number of fluorescent crown lines per tooth between Rotherham and Northallerton (Figures 1 and 2) may be due to the differences in the levels of atmospheric pollution. The fall in tetracycline administration after 1965 may be the result of two factors; first, a more critical attitude to tetracycline prescription in view of the widespread publicity highlighting their adverse effects and, secondly, and particularly applicable to Rotherham, the additional effect of reduction in atmospheric pollution.

\section{SUMmaRY}

All previously published surveys have indicated that the prevalence of tetracycline deposits in children's teeth is high and that the highest prevalence occurred in the teeth of the youngest children. The present survey compares the incidence of tetracycline deposits in the teeth of children living in two towns with different levels of atmospheric pollution. Although the level of tetracycline deposits remains high, there is a decline from a peak incidence occurring in 1960-65, and the survey suggests that environmental factors may exert a significant influence on the level of tetracycline administration.

We should like to thank Miss A. Potts, Principal Dental Officer to the North Riding of Yorkshire, for her co-operation during this study, and Miss S. Stones for technical assistance. 


\section{REFERENCES}

APTHORP, B. D. (1969). Hong Kong influenza. Brit. med. J., $1,49$.

BAKER, K. L., and STOREY, E. (1970). Tetracyclineinduced tooth changes, part 3 . Incidence in extracted first permanent molar teeth. Med. J. Aust., 1, 109.

BaNks, H. S. (1968). Antibiotics and the common cold. Lancet, 1, 425.

—, and Ritchie, J. M. (1969). Re-appraisal : a new look at the common cold. J. roy. Coll. gen. Practit., 18, 166.

Grossman, E. R., Walchek, A., and Freedman, H. (1971). Tetracyclines and permanent teeth: the relation between dose and tooth color. Pediatrics, 47, 567.

Lancet (1966). Tetracyclines and the teeth. Lancet, 1, 917.

LunN, J. E., KNowelden, J., and RoE, J. W. (1970). Patterns of respiratory illness in Sheffield junior schoolchildren. A follow-up study. Brit. J. prev. soc. Med., 24, 223.

Medical Officer of Health, Rotherham (1970). Annual reports.
Milch, R. A., Rall, D. P., and Tobie, J. E. (1957). Bone localization of the tetracyclines. J. nat. Cancer Inst., $19,87$.

MoYnahan, E. J. (1962). Tetracycline in teeth and bone. Lancet, 1, 969.

Mull, M. M. (1966). The tetracyclines. Amer. J. Dis. Child., 112, 483.

Saltzman, A. (1950). Fluorophotometric estimation of aureomycin in blood and urine. J. Lab. clin. Med., 35, के 123.

Shwachman, H., and Schuster, A. (1956). The tetracyclines. Applied pharmacology. Pediat. Clin. $N$. Amer., p. 295. [May].

STEWART, D. J. (1968). Tetracyclines: their prevalence in children's teeth. Brit. dent. J., 124, 318.

Wallman, I. S., and Hilton, H. B. (1962). Teeth pigmented by tetracycline. Lancet, 1, 827.

Witkop, C. J., and WoLf, R. O. (1963). Hypoplasia and intrinsic staining of enamel following tetracycline therapy. J. Amer. med. Ass., 185, 1008.

WEYMAN, J. (1965). The clinical appearances of tetracycline staining of the teeth. Brit. dent. J., 118, 289. 